\title{
Synergistic effect of malathion and estrogen on mammary gland carcinogenesis
}

\author{
GLORIA M. CALAF ${ }^{1,2}$ and CARLOS ECHIBURÚ-CHAU ${ }^{1}$ \\ ${ }^{1}$ Institute for Advanced Research, Tarapacá University, Arica, Chile; ${ }^{2}$ Center for Radiological Research, \\ Columbia University Medical Center, New York, NY, USA
}

Received March 6, 2012; Accepted April 24, 2012

DOI: $10.3892 /$ or.2012.1817

\begin{abstract}
Breast cancer is the most frequent malignancy diagnosed in women and is a classical model of hormone-dependent malignancy. Over the past 15-20 years, epidemiological studies have pointed to an increased breast cancer risk associated with prolonged exposure to female hormones. On the other hand, environmental chemicals such as malathion, an organophosphorous pesticide used to control a wide range of sucking and chewing pests of field crops, may be involved in the etiology of breast cancers. Results indicated that estrogen alone increased average number of lobules per $\mathrm{mm}^{2}$ of rat mammary glands in comparison to control and malathion alone at 30, 124, 240 and 400 days after 5-day treatments. On the other hand, malathion alone significantly increased the number of ducts in stage of proliferation at 10-240 days after 5-day treatments. Furthermore, markers for cancer detection such as mutant p53, c-myc, c-fos and CYPs proteins were overexpressed after treatments. Atropine, an anticholinergic drug, counteracted these effects when it was combined with malathion under similar conditions. The combination of malathion and estrogen synergistically increased number of lobules and ducts per $\mathrm{mm}^{2}$ of rat mammary glands after treatments and inducing mammary cancer. It can be concluded that combination of an environmental substance such as the pesticide malathion and an endogenous substance such as estrogen can enhance the deleterious effects in human mammary glands inducing cancer and atropine is able to diminish these effects.
\end{abstract}

\section{Introduction}

Breast cancer is the most frequent spontaneous malignancy diagnosed in women in the western world, and is a classical model of hormone-dependent malignancy. It may have both its genesis and cell growth influenced by hormonal factors since approxi-

Correspondence to: Dr Gloria M. Calaf, Instituto de Alta Investigación, Tarapacá University, Calle Antofagasta no. 1520, Arica, Chile

E-mail: gmc24@columbia.edu

Key words: pesticides, malathion, atropine, estrogen, rat mammary cancer mately one third of breast cancers is responsive to endocrine therapies (1-5). Environmental chemicals may also be involved in the etiology of breast cancers $(6,7)$. Many human tumors have been causally attributed to exposure to environmental carcinogens, pollutants, pesticides, drugs, ultraviolet light, radiation and tobacco (6). One of them is malathion [0, 0-dimethyl S-(1, 2-dicarbethoxy-ethyl)-phosphorodithioate], an organophosphorous pesticide extensively used to control a wide range of sucking and chewing pests of field crops. According to authors (8) exposure of the skin to this pesticide resulted in systemic absorption. Malathion is present in lotions and shampoos marketed for the treatment of head lice and mites in humans. Malathion is acetylcholinesterase (AchE) inhibitor and responsible for the hydrolysis of body choline esters, including acetylcholine (Ach) at cholinergic synapses $(9,10)$. The inhibition of these enzymes increases the availability of Ach, which in turn can stimulate cholinergic receptors producing both nicotinic and muscarinic effects in the organism such as muscle contractions and secretions in many glands (9). Such effects can be counteracted with atropine, a parasympatholytic alkaloid used as an antidote to AchE inhibitors $(9,10)$.

Estrogens have generally been considered beneficial, based on a variety of hormonal effects and the potential carcinogenic activity of estrogen-containing medications in humans has not been recognized for many years. However, in the past 15-20 years, epidemiological studies have pointed to an increased breast cancer risk associated with prolonged exposure to female hormones, since early onset of menarche, late menopause, hormone replacement therapy are associated with greater cancer incidence (9,11-16). Estrogen administration, a risk factor for humans increases with continuous doses of estrogen and with the length of treatment (17). Indeed, slightly elevated levels of circulating estrogens are also a risk factor for breast cancer $(18,19)$. This role of endogenous estrogen in human breast carcinogenesis has been supported by high serum or urine estrogen levels in breast cancer patients $(20,21)$. Furthermore, cohort studies have confirmed the strong relationship between endogenous estrogen levels and breast cancer risk (19,22-25).

Estrogens are associated with carcinogenic events in both humans and animals (26-31) and the exact effect of estrogens in breast cancer remains unclear at this time. Estrogens at physiologic and pharmacological levels have been implicated causally in a variety of experimental cancers as shown by the several investigators $(15,32)$. Since that time, many reports of tumor induction 
by estrogens have been published, and many rodent models have been introduced (33). The evidence for the carcinogenic activity of estrogens in animals has been deemed sufficient by the IARC to consider this hormone a carcinogen $(28,29,34)$. This conclusion is based on numerous tests of estrogens administered to rodents orally or subcutaneously. Such mice and rats increased the incidence of mammary tumors (35-43). In hamsters, a high incidence of malignant kidney tumors occurred in intact and castrated males $(26,27,44-47)$ and in ovariectomized females, but not in intact females (26).

Among the major metabolites of the estrogens are the catechol estrogens (CE), 2- and 4-hydroxylated estrogens (30). In general, the major metabolites are the 2-CE, whereas the 4-CE is the minor one. The pathway to give 4-CE is the one leading to the endogenous carcinogenic catechol estrogen-3, 4-quinones, 4-hydroxyestrone (4-OHE1) and 4-hydroxyestradiol (4-OHE2) are formed from estrone (E1) and estradiol (E2), which are biochemically interconvertible by the enzyme $17 \beta$-estradiol dehydrogenase. This inactivating pathway is in competition with the activation of $\mathrm{CE}$ to semiquinones and quinones; the oxidations are catalyzed by peroxidases and cytochrome P450 (CYP). CYP is an important component of the phase I drug-metabolizing system (30).

Investigations on DNA damage by steroidal estrogens via catechol estrogen metabolites have received special attention with the reports that consider the carcinogenic activity of 4-hydroxyestradiol (4-OHE2), comparable to that of estrogen in the hamster kidney tumor model (30). The 2-hydroxylation (2-OHE2) of steroidal estrogens is the major metabolic oxidation of estrogenic hormones in most mammalian species. Such oxidation is catalyzed in human or hamster liver by cytochrome P450 3A4 enzymes. Cytochrome P450 1A1 enzymes are the predominant estrogen 2-hydroxylases in extra hepatic tissues $(30,31)$. In humans, the predominant conversion of $17 \beta$-estradiol to 4-OHE2 has been detected in benign and malignant mammary tumors and in normal mammary tissue $(30,33)$. The human estrogen-4-hydroxylase activity has been identified as cytochrome P450 1B1, a novel extrahepatic isozyme detected specifically in mammary tissue, ovary, adrenal gland, uterus and several other tissues.

\section{Materials and methods}

Experimental designs. Thirty-nine-day-old virgin female Sprague-Dawley rats were obtained from the Catholic University of Chile (Santiago, Chile) and housed and bred in a barrier animal facility operated in accordance with the standards outlined in Guide for the Care and Use of Laboratory Animals (48). All animals were allowed continuous access to a standard laboratory chow diet (Champion, Santiago, Chile). Experimental design 1: i) control group received saline solution, $250 \mu \mathrm{g} / 100 \mathrm{~g}$ body weight (bw). Treated animals were injected subcutaneously (s.c.) for 5 days, twice a day with: ii) malathion (Fyfanon ${ }^{\mathrm{TM}}$, Cheminova, Denmark) that received $22 \mathrm{mg} / 100 \mathrm{~g}$ bw, iii) $17 \beta$-estradiol (Sigma-Aldrich Chemical Co., Milwaukee), $30 \mu \mathrm{g} / 100 \mathrm{~g}$ bw and iv) combination of both $(\mathrm{M}+\mathrm{E})$. The animals were sacrificed in three periods after 30, 124, 240 and 400 days post-treatment. Experimental design 2: i) control group received saline solution (s.c.), $250 \mu \mathrm{g} / 100 \mathrm{~g}$ bw. Treated animals were injected subcutaneously for 5 days, twice a day with: ii) malathion (M) (Fyfanon,
Cheminova) that received $22 \mathrm{mg} / 100 \mathrm{~g}$ bw, iii) atropine (Sigma), $250 \mu \mathrm{g} / 100 \mathrm{~g} \mathrm{bw}$, and iv) combination of malathion and atropine $(\mathrm{M}+\mathrm{A})$; at the dosages previously indicated. The $\mathrm{LD}_{50}$ values of the substances for malathion was $1,000 \mathrm{mg} / \mathrm{kg}$. However, the dose used in these experiments was $1 / 6$ th of the $\mathrm{LD}_{50}$ for malathion, which allowed a $100 \%$ survival of animals after a 5-day treatment. Animals were housed three per cage and palpated weekly to detect formation of tumors. The animals were sacrificed after 10, 20, 30, 60, 90, 124 and 240 days following a 5-day treatment. Tissues were excised and morphologically analyzed. Animals to be sacrificed were anesthetized by intraperitoneal injections of sodium pentobarbital $(8 \mathrm{mg} / 100 \mathrm{~g} \mathrm{bw})$ and opened by a midline incision from the pubis to the sub-maxillary area to remove the tissues. Mammary glands and palpable tumors were fixed in $10 \%$ neutral buffered, embedded in paraffin, then serially sectioned at a thickness of $5 \mu \mathrm{m}$ and stained with hematoxylin-eosin. Throughout histological studies the severity of mammary gland damage was evaluated by a scoring system which gave quantitative measurements. Histomorphometry was performed using a binocular microscope, in which a $1-\mathrm{mm}^{2}$ grid was installed in one of the oculars. Ten fields were studied with lens of 10x in an optical microscope (Olympus CX31). Five slides counted per animal to determine the number of ducts in stage of proliferation and lobules with hyaline casts in the mammary gland from control and treated animals. The damage was analyzed in five sectors per animal and the totality of fields was analyzed for morphological abnormalities. Zones without lobules filled with hyaline casts were graded with score $=0$. The damage in fifty lobules was scored according to scale from 10 to 30 points. Structures were graded as 10 when morphology and normal structure were present and there was lack of hyaline casts in lobules. Structures were graded as 20 when minor damage lobular structures were present and there were small hyaline casts inside. Structures were graded as 30 when and lobular structure had dilated tubules and there were hyaline casts in larger sizes and lobular structure had serious injuries and presence of large hyaline casts. Fifty ducts were classified according to scale from 10 to 30 points. The damage was analyzed in five sectors per animal and the totality of fields was analyzed for morphological abnormalities. Ducts without proliferation, i.e. with two to three layers were graded as 0 ; ducts with $>4$ layers and disorganized nuclei were graded from 10 to 30 , as layers increased in size. Comparison between treated groups and controls were made by Anova and Dunnet's test, with $\mathrm{P}<0.05$ and the test of hypothesis for difference of proportions $(\mathrm{P}<0.05)$.

Western blot analysis. Cells were treated with $1 \mathrm{ml}$ lysis buffer (pH 7.2) (50 mM Tris base; $1 \mathrm{mM}$ EDTA; $100 \mathrm{mM} \mathrm{NaCl} ; 1 \mathrm{mM}$ PMSF; $1 \mathrm{mM}$ orthovanadate; $0.1 \%$ Triton X-100) and centrifuged (10000 rpm x $10 \mathrm{~min}$ ). The supernatant with cellular proteins was dissolved in SDS-PAGE sample solution $(60 \mathrm{mM}$ Tris, $\mathrm{pH}$ $6.5 ; 10 \%(\mathrm{w} / \mathrm{v})$ glycerol; $5 \%(\mathrm{w} / \mathrm{v}) \beta$-mercaptoethanol; $20 \%(\mathrm{w} / \mathrm{v})$ SDS; $0.025 \%$ (w/v) bromophenol blue) and denatured by boiling (5 min), and vortex mixing $(2 \times 30 \mathrm{seg})$. The total amount of protein was $20 \mu \mathrm{g}$ in each lane with standard protein markers (Bio-Rad Laboratories, Hercules, CA). After fractionation by SDS-PAGE on gels, proteins were electro-blotted onto nitrocellulose membrane (Amersham Biosciences, UK) using a blotting apparatus (Bio-Rad Laboratories). SDS-PAGE blots were blocked for $2 \mathrm{~h}$ in $10 \%$ defatted dry milk-TBS- $0.1 \%$ Tween-20 and then incu- 

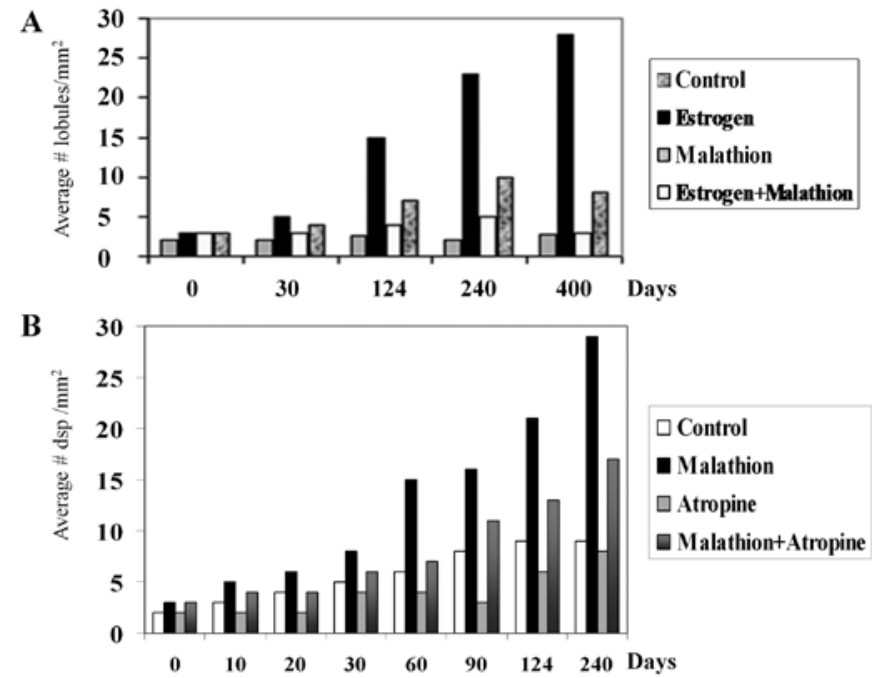

Figure 1. (A) Graphs that show the effect of estrogen, malathion and combination of both as average number of lobules with secretion per $\mathrm{mm}^{2}$ of rat mammary glands $0,30,124,240$ and 400 days of after a 5-day treatment. (B) Malathion and atropine as average number of ducts in stage of proliferation (dsp) per $\mathrm{mm}^{2}$ of rat mammary glands $10,20,30,60,90,124$ and 240 days after a 5-day treatment.

bated for $2 \mathrm{~h}$ at room temperature with corresponding primary antibodies (1:200) as CYP1A1 (sc-9828), mp53 (sc-99), c-myc (sc-42) and c-fos (sc-7202) (all from Santa Cruz Biotechnology, Santa Cruz, CA, USA) and then followed by incubation with secondary peroxidase-conjugated (1:5000) (all from Santa Cruz Biotechnology) in 5\% defatted dry milk-TBS-0.1\% Tween-20. All steps were performed at room temperature, and blots were rinsed between incubation steps with TBS- $0.1 \%$ Tween-20. Cell blots were probed with mouse anti- $\beta$-actin antibody as control. Immunoreactive bands were visualized by using the
ECL $^{\mathrm{TM}}$ Western Blotting Detection Reagent detection method (Amersham, Dübendorf, Switzerland) and exposure of the membrane to X-ray film. Protein determination was performed using the bicinchoninic acid method (Bio-Rad Laboratories) and bovine serum albumin as standard.

\section{Results}

Results indicated that estrogen alone increased the average number of lobules per $\mathrm{mm}^{2}$ of rat mammary glands in comparison to control and malathion treatment alone at 30, 124, 240 and 400 days after a 5-day treatment. Fig. 1A shows the effect of estrogen, malathion and combination of both as average number of lobules with secretion per $\mathrm{mm}^{2}$ of rat mammary glands at $30,124,240$ and 400 days after a 5-day treatment. Lobular carcinomas derived from such lobules were found at 240 days of the 5-day treatment of estradiol. Mammary gland of estrogen-treated animal had altered lobules full of hyaline casts. The control rats had normal duct formation. However, the malathion treated animals showed a significant $(\mathrm{P}<0.05)$ increase in the size of ducts in stage of proliferation $\left(\mathrm{dsp} / \mathrm{mm}^{2}\right)$ of the mammary gland, as well as in the number of the epithelial layers in comparison to controls at 10 and 20 days after a 5-day treatment, as well as 30 , 60, 90, 124 and 240 days (Fig. 1B). Atropine and combination of both diminished such an effect from 10 to 240 days.

Representative images of cross section of mammary gland of control and treated animals can be seen in Fig. 2. A normal lobule is shown in Fig. 2A. Fig. 2B and C represent lobules filled with hyaline casts or secretion of an estrogen-treated rat. Lobules increased in size with the time and mammary gland tumors were induced by the effect of estrogen alone at 240 days after a 5-day treatment with well characterized lobule formation. Fig. 2D and E correspond to representative images of control and malathiontreated rat, respectively. Fig. 2F shows the atrophic ducts induced by atropine.
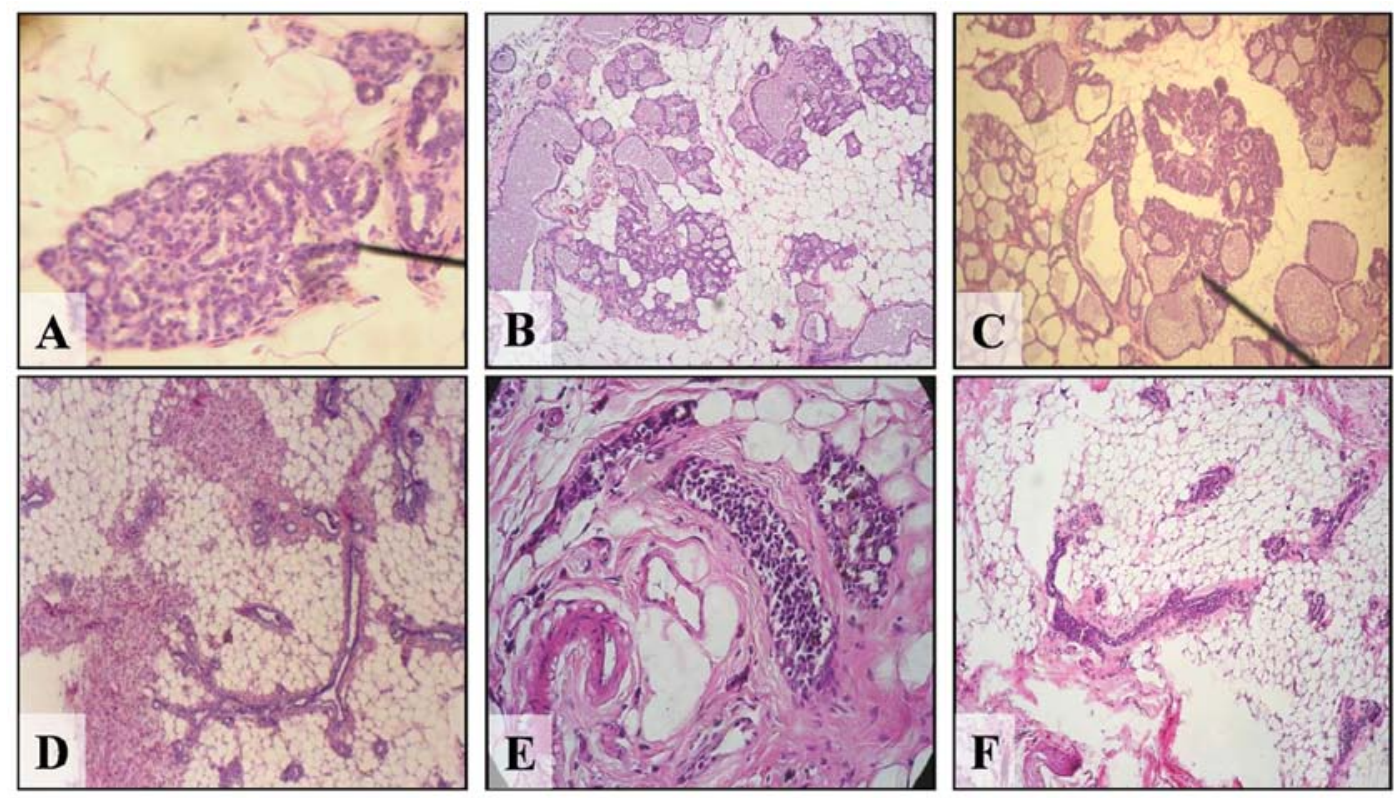

Figure 2. Cross section $(5 \mu \mathrm{M})$ of representative images of rat mammary gland of: (A) control animal with normal lobule; (B and C) estrogen-treated animal with altered lobules full of hyaline casts; (D) normal duct. Atrophic ducts found in (E) malathion and (F) malathion plus atropine-treated animals 240 days after a 5-day treatment. 
$\mathbf{A}$

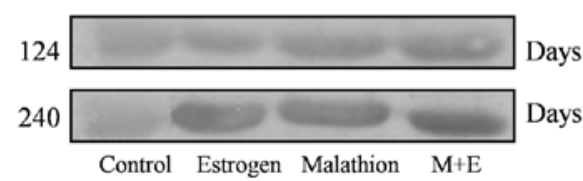

B

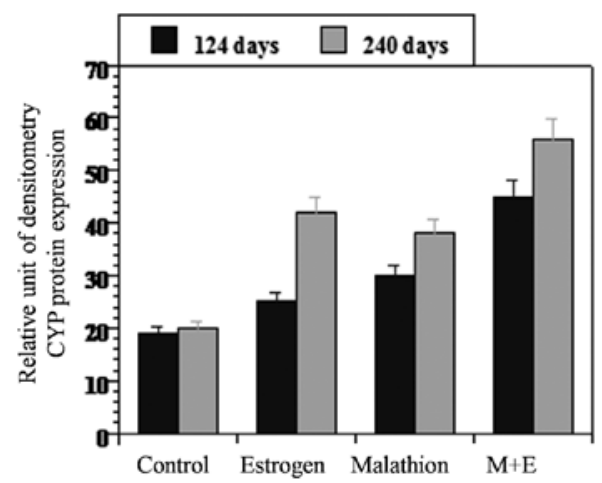

C mp53 protein expression

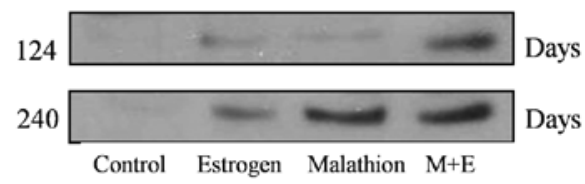

D

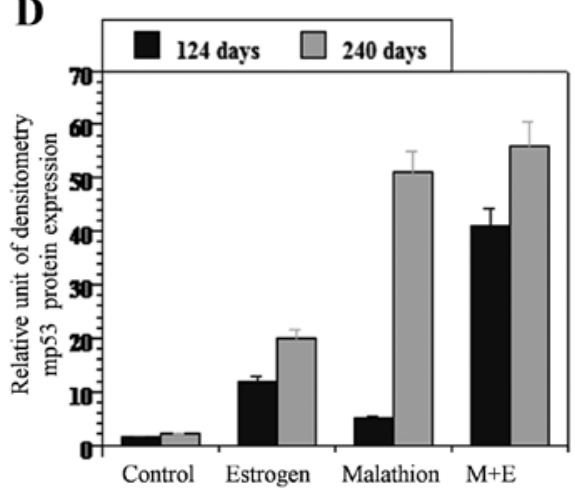

Figure 3. Effect of estrogen, malathion and combination of both (M+E) on western blot analysis of: (A) CYP1A1 and (C) mp53 protein expression after 124 and 240 days; and (B and D) relative unit of densitometry of such an expression.

A

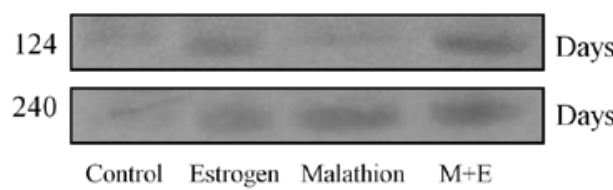

B

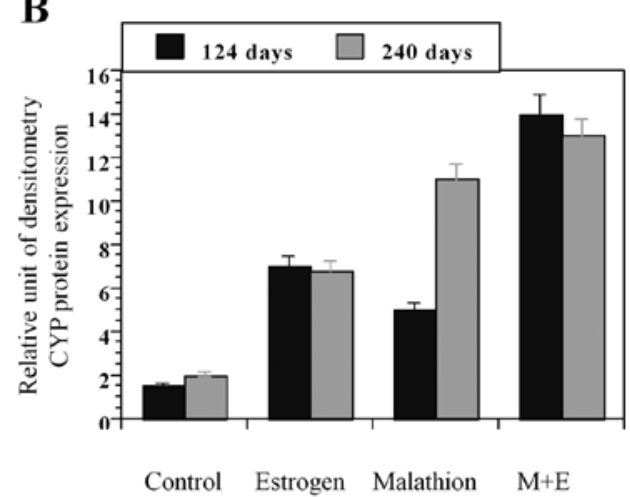

C c-fos protein expression

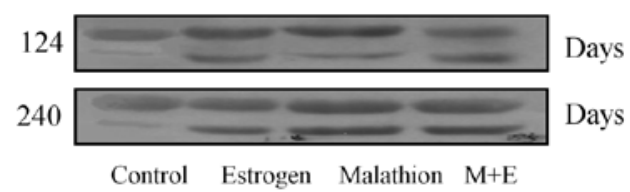

D

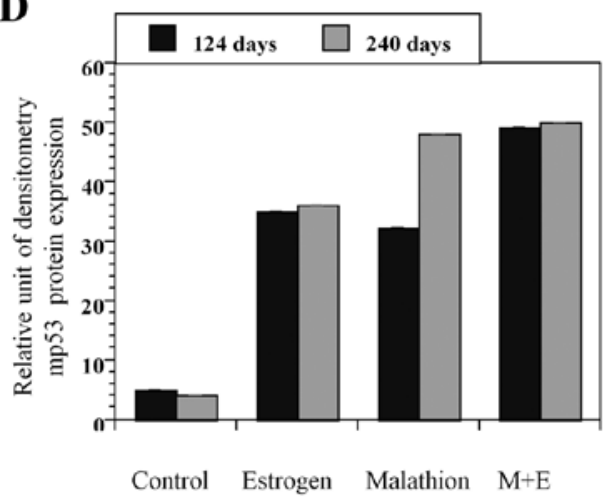

Figure 4. Effect of estrogen, malathion and combination of both (M+E) on protein expression determined by western blot analysis of: (A) c-myc and (C) c-fos after 124 and 240 days; (B and D) relative unit of density of such an expression.

Fig. 3 shows the effect of estrogen, malathion and combination of both on western blot analysis of CYP 1A1 (Fig. 3A) and mp53 (Fig. 3C) protein expression after 124 and 240 days, respectively. Fig. 3B and D correspond to the relative unit of densitometry of such an expression. On the other hand, estrogen and malathion alone and in combination increased c-myc (Fig. 4A) and c-fos (Fig. 4C) protein expression after 124 and 240 days in comparison to control as seen by western blot analysis and its quantification (Fig. 4B and 4D). Such expressions were also higher in estrogen-treated animals when compared to controls after 124 and 240 days.
The increase of proliferative ducts induced by the effect of malathion after 10 and 20 days, was coincident with the increase in mutant p53 protein expression by western blot analysis as quantified by the relative unit of densitometry (Fig. 5A). Atropine and combination of both diminished such effect after 20 days of a 5-day treatment. Control animals did not develop any kind of tumors. Combination of malathion and estrogen induced greater cellular changes in the rat mammary glands than estrogen or malathion alone (Fig. 5A). Increased amount of proliferative ducts and secretory lobules were induced by these two substances showing rat mammary gland tumor formation 
A

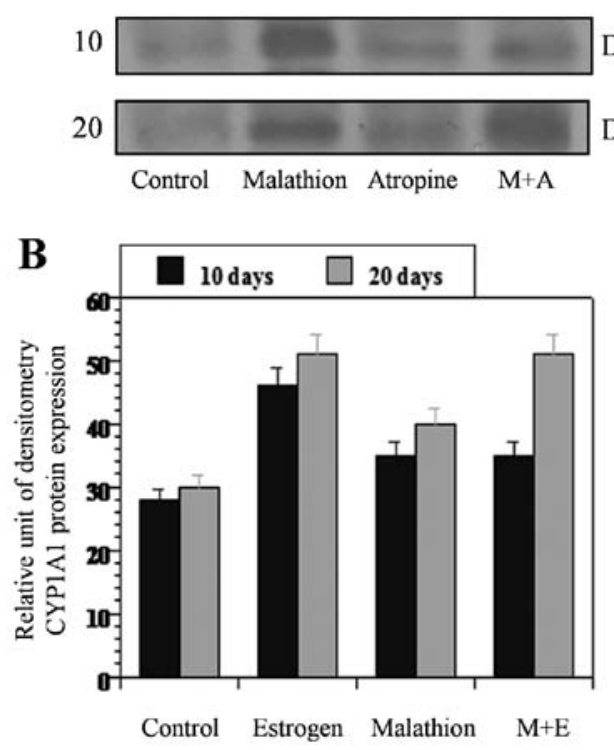

C

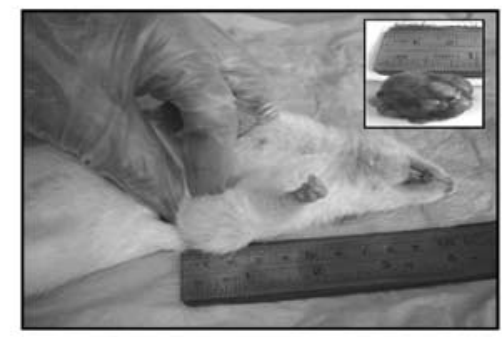

D

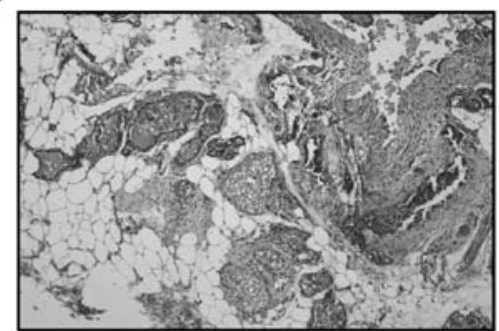

Figure 5. Effect of malathion, atropine and combination of both (M+A) on protein expression determined by western blot analysis of: (A) mp53 10 and 20 days after treatment. Effect of malathion, estrogen and combination of both (M+E) on protein expression determined by western blot analysis of CYP1A1 shown as (B) relative unit of intensity of densitometry 10 and 20 days after treatment. (C) Rat mammary gland tumor induced by the effect of malathion and estrogen $(\mathrm{M}+\mathrm{E})$ at 240 days after a 5-day treatment. See insert after tumor removal. (D) Cross section of a representative tumor formed in this group of animals.

at 240 days after a 5-day treatment. Mammary gland tumor formed by the effect of these substances was characterized by the presence of ducts in stage of proliferation and secretory lobules (Fig. 5C and D). Analysis of heart, intestinal tract and ovaries did not show any tumors. However, lung and kidney were affected as was previously reported (data not shown).

\section{Discussion}

The high level of cell proliferation and differentiation that occurs during mammary gland development makes this organ an attractive experimental animal model for examining its susceptibility to different carcinogenic actions. Cell proliferation in the mammary gland is not a random event, but is intimately related to both topography of the mammary parenchyma and specific stages of the gland development that are modulated by age, hormonal variations and parity history. The mammary gland is a complex organ that undergoes continuous changes under the influence of body growth as well as cyclic hormonal stimulation from birth to senescence. It is composed of a single primary or main lactiferous duct that branches into three to five secondary ducts at birth and during the first week of postnatal life. The ducts are narrow and straight and end in small club-shaped terminals, called terminal end buds. Different compartments, such as ducts, ductules, and intralobular terminal ducts, have been observed in rats. The intralobular terminal duct is equivalent to the terminal ductal lobular unit in the human breast, considered the site of origin of human breast carcinomas $(49,50)$.

Mammary gland tumors formed in the presence of either estrogen or malathion are similar to lobular and ductal carcinomas, respectively described in breast biopsies according to World Health Organization. Our results showed transformation in the epithelium of ducts while they were in the process of development. These results indicated that the proliferative changes observed in such structures may have induced the formation of mammary ductal carcinomas.

In contrast to potent carcinogens, which induced mammary carcinomas in $100 \%$ of intact females Sprague-Dawley rats by chemical carcinogens, such as dimethylbenz $[\alpha]$ anthracene (DMBA), organophosphorous pesticides seem to have a slow and less infiltrating and potent effect. Tumor incidence of 94-100\% was obtained when DMBA was administered to rats 30-55 days of age. However, the highest number of tumors per animal was observed when the carcinogen was given to animals when they were 40-46 days of age, a period when terminal end buds were most actively differentiating into alveolar buds (49). The administration of DMBA to virgin rats of different ages induced tumors with an incidence that was directly proportional to the density of highly proliferative structures.

Our previous study (51) examined whether pesticides were able to induce malignant transformation of the rat mammary gland and whether alterations induced by these substances increased the cholinergic activation influencing such transformation. We have demonstrated that parathion and malathion, formed 14.3 and $24.3 \%$ of rat mammary tumors, respectively, that correlated with the greater density of ducts in the mammary gland present in the 44 day-old treated animals. We postulated that it is possibly through acetylcholinesterase inhibition since atropine decreased such effects, as corroborated here. These results showed that malathion increased cell proliferation of terminal end buds of the 44-day-old mammary gland of rats, followed by formation of $24.3 \%$ of mammary carcinomas, respectively, after $\sim 28$ months. At the same time, acetylcholinesterase activity decreased in the serum of these animals from $9.78 \pm 0.78 \mathrm{U} / \mathrm{ml}$ in the control animals to $3.88 \pm 0.44 \mathrm{U} / \mathrm{ml}$ in malathion-treated groups. However, atropine alone induced a significant $(\mathrm{P}<0.05)$ decrease in the acetylcholinesterase activity from the control value of $9.78 \pm 0.78$ to $4.38 \pm 0.10$ for atropine alone, to $2.39 \pm 0.29$ 
for atropine with malathion, and there was no mammary tumor formation. These results indicated that organophosphorous pesticides induce changes in the epithelium of mammary gland influencing the process of carcinogenesis, and such alterations occur at the level of the nervous system by increasing the cholinergic stimulation.

Estrogen in combination with an organophosphorous pesticide such as malathion can produce several injuries also in kidney tissue, e.g. increase in glomerular hypertrophy, damage in the convoluted tubules, and malignant proliferation in cortical and hilium areas. It is possible that the oxidative stress caused by malathion exposure enhances the deleterious effects of $17 \beta$-estradiol (52). The level of injuries found in kidney tissue suggested an increased oxidative stress caused by treatment of malathion in combination with estrogen. The grade of damage can be serious and can develop tumors in urothelium of the hilium. Previous studies also showed that $17 \beta$-estradiol in combination with pesticides as parathion and malathion induced malignant transformation of lung in rats (53).

In conclusion, the combination of the environmental substance malathion, extensively used in Latin American and in many other countries, and an endogenous substance such as estrogen can induce deleterious effects in the humans by inducing breast cancer. Thus, these studies are relevant to understanding the possible effects of these agents that through their control can contribute to a decrease in this disease.

\section{Acknowledgements}

The technical assistance of Guiliana Rojas Ordoñez and Georgina Vargas Marchant are greatly appreciated. The authors are sincerely thankful by support provided by FONDECYT grant no. 1080482 (GMC) and Convenio de Desempeño Universidad de Tarapacá-Mineduc, Chile.

\section{References}

1. Dickson RB, Gelmann EP, Knabbe C, et al: Mechanisms of estrogenic and antiestrogenic regulation of growth of human breast carcinoma. In: Hormonal Manipulation of Cancer: Peptides, Growth Factors, and New (Anti) Steroidal Agents. Klijn JGM (ed.) Raven Press, New York, NY,pp381-403, 1987.

2. Clark GM and McGuire WL: Steroid receptors and other prognostic factors in primary breast cancer. Semin Oncol 18: 20-25, 1989.

3. Clarke RB, Howell A, Potten CS, et al: Dissociation between steroid receptor expression and cell proliferation in the human breast. Cancer Res 57: 4987-4991, 1997.

4. Henderson BE, Pike MC and Ross RK: Epidemiology and risk factors. In: Breast Cancer: Diagnosis and Management Bonadonna G (ed.) John Wiley and Sons Ltd., New York, NY, pp1-17, 1984.

5. Henderson BE, Ross RK and Pike MC: Hormonal chemoprevention of cancer in women. Science 259: 633-638, 1993.

6. Perera FP: Environment and cancer: who are susceptible? Science 278: 1068-1073, 1997.

7. McLachlan JA: Functional toxicology: a new approach to detect biologically active xenobiotics. Environ Health Perspect 101: 386-387, 1995.

8. Taylor P: Anticholinesterase agents. In: The Pharmacological Basis of Therapeutics. Goodman Gilman A, Rall TW, Nies AS and Taylor P (eds.) Pergamon Press Inc., New York, NY, pp131-147, 1990.

9. Klaasen C: Nonmetallic environmental toxicants: air pollutants, solvents and vapors, and pesticides. In: The Pharmacological Basis of Therapeutics. Goodman Gilman A, Rall TW, Nies AS and Taylor P (eds.) Pergamon Press Inc., New York, NY, pp1615-1635, 1990.
10. Silman I and Futerman A: Modes of attachment of acetylcholinesterase to the surface membrane. Eur J Biochem 170: 11-20, 1987.

11. Krieger N: Rising incidence of breast cancer. J Natl Cancer Inst 80: 2-3, 1988

12. Krieger N: Exposure, susceptibility, and breast cancer risk: a hypothesis regarding exogenous carcinogens, breast tissue development, and social gradients, including black/white differences, in breast cancer incidence. Breast Cancer Res Treat 13: 205-223, 1989.

13. Kelsey JL, Gammon MD and John EM: Reproductive factors and breast cancer. Epidemiol Rev 15: 36-47, 1993.

14. Kelsey JL and Bernstein L: Epidemiology and prevention of breast cancer. Annu Rev Public Health 17: 47-67, 1996.

15. Lippman M, Bolan G and Huff K: The effects of estrogens and antiestrogens on hormone-responsive human breast cancer in long-term tissue culture. Cancer Res 36: 4595-4601, 1976.

16. Dickson RB and Lippman ME: Control of human breast cancer by estrogen, growth factors, and oncogenes. Cancer Treat Res 40: 119-165, 1988.

17. Key TJ and Pike MC: The dose-effect relationship between 'unopposed' oestrogens and endometrial mitotic rate: its central role in explaining and predicting endometrial cancer risk. Br J Cancer 57: 205-212, 1988.

18. Feigelson HS and Henderson BE: Estrogens and breast cancer. Carcinogenesis 17: 2279-2284, 1996.

19. Bernstein L: The epidemiology of breast cancer. LOWAC J 1: 7-13, 1998.

20. Toniolo PG, Levitz M,Zeleniuch-Jacquotte A, et al: A prospective study of endogenous estrogens and breast cancer in postmenopausal women. J Natl Cancer Inst 87: 190-197, 1995.

21. Adlercreutz H, Gorbach SL, Goldin BR, et al: Estrogen metabolism and excretion in Oriental and Caucasian women. J Natl Cancer Inst 86: 1076-1082, 1994.

22. Berrino F, Muti P, Micheli A, et al: Serum sex hormone levels after menopause and subsequent breast cancer. J Natl Cancer Inst 88: 291-296, 1996.

23. Shimizu H, Ross RK, Bernstein L, et al: Serum oestrogen levels in postmenopausal women: comparison of American whites and Japanese in Japan. Br J Cancer 62: 451-453, 1990.

24. Bernstein L, Yuan JM, Ross RK, et al: Serum hormone levels in pre-menopausal Chinese women in Shanghai and white women in Los Angeles: results from two breast cancer case-control studies. Cancer Causes Control 1: 51-58, 1990.

25. Bernstein L, Ross RK, Pike MC, et al: Hormone levels in older women: a study of post-menopausal breast cancer patients and healthy population controls. Br J Cancer 61: 298-302, 1990.

26. Kirkman H: Estrogen-induced tumors of the kidney. III. Growth characteristics in the Syrian hamster. Natl Cancer Inst Monogr 1: 1-57, 1959.

27. Li JJ, Li SA, Klicka JK, et al: Relative carcinogenic activity of various synthetic and natural estrogens in the Syrian hamster kidney. Cancer Res 43: 5200-5204, 1983.

28. International Agency for Research on Cancer (IARC): IARC Monographs on the Evaluation of Carcinogenic Risks to Humans. Vol. 21 Scientific Publications, IARC, Lyon, pp279-362, 1979.

29. International Agency for Research on Cancer (IARC): IARC Monographs on the Evolution of Carcinogenic Risks to Humans. IARC Suppl 7, Lyon, pp280-285, 1987.

30. Cavalieri EL, Stack DE, Devanesan PD, et al: Molecular origin of cancer: catechol estrogen-3,4-quinones as endogenous tumor initiators. Proc Natl Acad Sci USA 94: 10937-10942, 1997.

31. Chakravarti D, Mailander P, Cavalieri E, et al: Estrogen-DNA damage in mouse skin $\mathrm{H}$-ras gene is mutated by error prone repair. Proc Am Assoc Cancer Res 41: 107, 2000.

32. Segaloff A and Maxfield WS: The synergism between radiation and estrogen in the production of mammary cancer in the rat. Cancer Res 31: 166-168, 1971.

33. Calaf GM and Garrido F: Catechol estrogens as biomarkers for mammary gland cancer. Int J Oncol 39: 177-183, 2011.

34. International Agency for Research on Cancer (IARC): IARC Monographs on the Evolution of Carcinogenic Risks to Humans. Vol. 72 Hormonal Contraception and Postmenopausal Hormone Therapy, IARC, Lyon, 1999.

35. Huseby RA: Demonstration of a direct carcinogenic effect of estradiol on Leydig cells of the mouse. Cancer Res 40: 1006-1013, 1980.

36. Highman B, Norwell MJ and Shellenberger TE: Pathological changes in female $\mathrm{C} 3 \mathrm{H}$ mice continuously fed diets containing diethylstilbestrol or 17beta-estradiol. J Environ Pathol Toxicol 1: $1-30,1978$. 
37. Highman B, Greenman DL, Norvell MJ, Farmer J and Shellenberger TE: Neoplastic and preneoplastic lesions induced in female $\mathrm{C} 3 \mathrm{H}$ mice by diets containing diethylstilbestrol or 17beta-estradiol. J Environ Pathol Toxicol 4: 81-95, 1980.

38. Highman B, Roth SI and Greenman DL: Osseous changes and osteosacomas in mice continuously fed diets containing diethylstilbestrol or 17beta-estradiol. J Natl Cancer Inst 67: 653-662, 1981.

39. Nagasawa $H$, Mori $T$ and Nakajima Y: Long-term effects of progesterone or diethylstilbestrol with or without estrogen after maturity on mammary tumorigenesis in mice. Eur J Cancer 16: $1583-1589,1980$

40. Inoh A, Kamiya K, Fujii Y and Yokoro K: Protective effects of progesterone and tamoxifen in estrogen-induced mammary carcinogenesis in ovariectomized W/Fu rats. Jpn J Cancer Res 76: 699-704, 1985

41. Noble RL, Hochachka BC and King D: Spontaneous and estrogenproduced tumors in $\mathrm{Nb}$ rats and their behavior after transplantation. Cancer Res 35: 766-780, 1975.

42. Shull JD, Spady TJ, Snyder MC, Johansson SL and Pennington KL: Ovary-intact, but not ovariectomized female ACI rats treated with 17 beta-estradiol rapidly develop mammary carcinoma. Carcinogenesis 18: 1595-1601, 1997.

43. Welsch CW: Host factors affecting the growth of carcinogeninduced rat mammary carcinomas: a review and tribute to Charles Brenton Huggins. Cancer Res 45: 3415-3443, 1985.

44. Li JJ and Li SA: Estrogen-induced tumorigenesis in hamsters: roles for hormonal and carcinogenic activities. Arch Toxicol 55: 110-118, 1984
45. Li JJ and Li SA: Estrogen carcinogenesis in Syrian hamster tissues: role of metabolism. Fed Proc 46: 1858-1863, 1987.

46. Bhat HK, Calaf GM, Hei TK, et al: Critical role of oxidative stress in estrogen-induced carcinogenesis. Proc Natl Acad Sci USA 100: 3913-3918, 2003.

47. Liehr JG: Genotoxic effects of estrogens. Mutat Res 238: 269-276, 1990.

48. Institute of Animal Laboratory Resources: Guide for the Care and Use of Laboratory Animals. National Academy Press, Washington, DC, 1996.

49. Russo J and Russo IH: Mammary tumorigenesis. Prog Exp Tumor Res 33: 175-191, 1991.

50. Wellings SR, Jensen HM and Marcum RG: An atlas of subgross pathology of the human breast with special reference to possible precancerous lesions. J Natl Cancer Inst 55: 231-273, 1975.

51. Cabello G, Valenzuela M, Vilaxa A, et al: A rat mammary tumor model induced by the organophosphorous pesticides parathion and malathion, possibly through acetylcholinesterase inhibition. Environ Health Perspect 109: 471-479, 2001.

52. Alfaro-Lira S, Pizarro-Ortiz M and Calaf GM: Malignant transformation of rat kidney induced by environmental substances and estrogen. Int J Environ Res Public Health (In Press).

53. Echiburu-Chau $\mathrm{C}$ and Calaf GM: Rat lung cancer induced by malathion and estrogen. Int J Oncol 33: 603-611, 2008. 